Rev. Adm. Saúde (On-line), São Paulo, v. 20, n. 80: e249, jul. - set. 2020, Epub 30 set. 2020 http://dx.doi.org/10.23973/ras.80.249

PERSPECTIVAS

\title{
Um presente de despedida da minha mãe
}

Katherine A. Wayman, M.D

Ainda na praia, depois de fazer em minha mãe um exame neurológico, com martelo de reflexos no seu joelho, cometi um erro que jamais teria cometido com um paciente. "Mãe", eu disse, "há algumas descobertas sutis. Você precisa de uma ressonância magnética, mas não se preocupe - não é como se você tivesse um tumor no cérebro." Aconselhei minha mãe a consultar seu médico de família quando voltasse para casa das nossas férias e, quando seus sintomas pioraram, disse-Ihe que fosse ao pronto-socorro. Então, quando minha mãe passou o telefone para o médico de emergência rural que lutava para pronunciar "corpo caloso" enquanto lia para mim o relatório da ressonância magnética, meu medo subconsciente foi confirmado. Cheguei na noite seguinte ao pequeno hospital comunitário e minha mãe me cumprimentou com o mesmo sorriso entusiasmado e de olhos arregalados que eu conhecia desde que era bebê, só que agora com leve fraqueza no lado direito do rosto.

Ela estava esperando uma transferência para a neurocirurgia no grande centro urbano a 3 horas de distância, mas nos disseram que isso poderia levar vários dias, e eu mal podia esperar. Consultei com meu amigo neurologista que morava no meio oeste ("é só fazer alta a pedido!"), levei minha mãe para o carro onde nos esperava sua parceira Kate. Com minha mãe no banco de trás e Kate dirigindo apressada, partimos. Minha mãe, olhando pela janela aberta, com seu cabelo curto, grisalho, soprado pelo vento, seu pescoço esticado para sorver os últimos ares da praia, enquanto acelerávamos em direção à cidade. Kate gritou acima do som do vento: "Estamos fugindo como Thelma e Louise!" e minha mãe disse ironicamente: "Todos nós sabemos como isso acabou."

Assim que chegamos ao pronto-socorro e ela foi levada de volta ao médico da triagem, senti que poderia ser apenas "a filha". Mas durante todo o seu tempo no hospital, minha mãe nunca perderia a chance de me apresentar como sua filha, "a neurologista".

Durante os oito dias de exames e aguardando a biópsia cerebral, minha mãe recebeu sua "corte" em seu quarto de hospital. Amigos vieram de todo o país. Todos nós discutimos os planos para seu casamento com Kate, ainda esperançosos de que pudesse ocorrer em casa. Também discutimos os planos para o funeral, e minha mãe, que cresceu na Ásia, sempre amou a ideia de 
pessoas chinesas chorando em seu velório. Ela desistiu dessa ideia rapidamente, porém, com medo de assustar seus jovens netos.

Nunca fomos uma família que evitava discussões sobre morte ou doença. Minha mãe ficou viúva aos 28 anos e, a consciência de nossa família sobre a morte, só foi ampliada quando ela foi diagnosticada com câncer de mama aos 30 anos. Lembro-me de várias discussões detalhadas do tipo "e se" naquela época. Portanto, era natural fazer perguntas muito específicas à minha mãe sobre com o que ela poderia viver e o que mais valorizava. Passamos por vários cenários, e chegou a este: "se eu não posso sentar no chão da sala e brincar com meus netos, eu não quero viver". Ela deixou claro que valorizava sua mobilidade, seu jogo de golfe e sua fala. Se não houvesse nenhum tratamento que pudesse garantir todas essas habilidades, ela queria poder morrer, de forma rápida e sem dor.

Minha mãe fez uma biópsia cerebral no dia do Halloween e não faltaram piadas sobre os marcadores cirúrgicos do tipo monstro de Frankenstein que foram colocados naquela manhã. Quando o neurocirurgião saiu da sala de cirurgia, ele confirmou o pior: "É um câncer na glia".

Fiquei com minha mãe na UTI, aquela noite, sob a tortura de exames neurológicos, de hora em hora. Ao sair da sedação, estava hemiplégica com afasia moderada. Garantiram-me que o agravamento do déficit era decorrente de um sangramento intraoperatório e que ela provavelmente iria melhorar, mas eu sabia que ela tinha cruzado a fronteira e que era meu trabalho garantir o desfecho que ela desejava.

Encontrei uma resistência notável quando, menos de 12 horas após a biópsia de minha mãe, solicitei uma consulta de cuidados paliativos e uma mudança para apenas medidas de conforto. Enfermeiras, residentes e atendentes alertaram que ela ainda estava sob os efeitos da sedação e que poderia melhorar e se sentir diferente. Ofereceram-nos consultas de oncologia e radiação oncológica. Percebi quantas vezes em meu treinamento e carreira eu também pratiquei sem uma perspectiva maior em mente - quantas vezes eu continuei a verificar exames de laboratório, fazendo imagens e me concentrando em pequenos detalhes, porque é assim que é feito. Se eu não tivesse tido uma discussão detalhada com minha mãe, sobre os resultados potenciais, eu poderia ter atrasado esta decisão. Talvez eu tivesse concordado em seguir os exames neurológicos um pouco mais na UTI, repetir mais alguns exames, considerada uma reabilitação subaguda, já que sua morte não era iminente. Mas havíamos discutido exatamente esse cenário, e cada minuto na UTI roubava a paz de minha mãe. Se confrontada com um câncer cerebral terminal e déficits significativos, ela só queria se casar com Kate, sua parceira de 20 anos, e então voar para Vermont para ver seus netos antes de ter uma "morte com dignidade" indolor.

Era o outono de 2013, e a Lei de Morte com Dignidade de Vermont, em vigor apenas desde maio anterior e sua aplicação não tinha sido testada suficientemente. Não tive coragem de dizer a minha mãe que, para obter os benefícios da lei ela era obrigada a ser residente em Vermont e que havia outras barreiras, como o agravamento da afasia. Depois de chegar ao hospital 
de cuidados paliativos em Vermont, minha mãe comunicou seus desejos ao médico. Este médico sentou-se com minha mãe, ouviu suas histórias, entendeu o que ela mais valorizava e assegurou-lhe que, embora ela não fosse uma candidata ao suicídio assistido por médico, havia outras opções para garantir uma morte com dignidade - "Por exemplo, você poderia parar de comer e beber." Depois de uma pausa, minha mãe perguntou: "O que mais você tem? "'

Nos dias seguintes, com visitantes e cantores no hospital, enchendo a sala, houve uma mudança em minha mãe. Ela não estava mais sorrindo. Ela não estava interagindo com as enfermeiras. Seu médico reconheceu seu sofrimento psíquico e ofereceu sedação paliativa que apressaria a morte. No dia seguinte, minha mãe foi sedada e cinco dias depois deu seu último suspiro. Não me lembro das últimas palavras dela antes de ser sedada, mas, sinceramente, não importava - nas quatro semanas desde o diagnóstico, nada havia deixado de ser dito.

Minha mãe certamente poderia ter vivido vários meses a mais com intervenções médicas contínuas, a um grande custo financeiro e emocional. Foi um presente para nós que ela fosse tão decidida em seus desejos e que não houvesse ambiguidade quanto ao seu prognóstico. Essas condições nem sempre se aplicam e, como médicos, temos sido testemunhas e parte de muitos finais lamentáveis e prolongados. Sou grata porque, conforme sua vida se aproximava do fim, pude usar meu conhecimento do sistema médico, neurologia e os valores de minha mãe para ajudá-la a ter uma boa morte. Mas sou muito grata porque minha mãe, que sempre teve medo da morte, me mostrou como abrir mão disso, no final.

Este artigo é reprodução em tradução livre do original:

\section{A Farewell Gift from My Mother}

Katherine A. Wayman, M.D

N Engl J Med 2020; 383:1204-1205

DOI: 10.1056/NEJMp2002103

(C) This is an Open Access article distributed under the terms of the Creative Commons Attribution License, which permits unrestricted use, distribution, and reproduction in any medium, provided the original work is properly cited 